\title{
EFICIÊNCIA do REATOR SEQÜENCIAL EM BATELADA (RSB) NA REMOÇÃO DE NITROGÊNIO NO TRATAMENTO DE ESGOTO DOMÉSTICO COM DQO BAIXA
}

\section{THE SEQUENCING BATCH REACTOR (SBR) EFFICIENCY IN THE REMOVAL OF NITROGEN ON THE TREATMENT OF DOMESTIC SEWAGE WITH LOW COD}

\section{LUIZ FERNANDO DE ABREU CYBIS}

Ph.D. em Engenharia Sanitária e Ambiental pela The University of Leeds, Inglaterra Professor do Instituto de Pesquisas Hidráulicas da Universidade Federal do Rio Grande do Sul

\section{ALTEMAR VILAR DOS SANTOS}

Mestre em Saneamento pela Universidade Federal da Paraíba

Doutorando do Programa de Pós-Graduação em Recursos Hídricos e Saneamento Ambiental do Instituto de Pesquisas Hidráulicas da Universidade Federal do Rio Grande do Sul e Professor do Centro Federal de Educação Tecnológica da Bahia

\section{GINO ROBERTO GEHLING}

Doutor em Engenharia Ambiental pela Universitat Politécnica de Catalunya, Espanha, Professor do Instituto de Pesquisas Hidráulicas da Universidade Federal do Rio Grande do Sul

Prêmio Enaldo Cravo Peixoto - 22 ${ }^{\circ}$ Congresso Brasileiro de Engenharia Sanitária e Ambiental, Joinville - SC, 2003

\section{RESUMO}

Este trabalho tem como objetivo avaliar a eficiência e a estabilidade do RSB na remoção de nitrogênio no tratamento de esgoto doméstico com DQO baixa. O reator utilizado no experimento possui volume de trabalho de $600 \mathrm{~L}$ e trata $1200 \mathrm{~L} / \mathrm{d}$ de esgoto bruto em três bateladas de oito horas. A partir dos dados obtidos na pesquisa, observou-se que o reator seqüencial em batelada possibilitou a remoção média de nitrogênio total igual a $88 \%$ no tratamento de esgoto doméstico com DQO média de $257 \mathrm{mg} / \mathrm{L}$. A remoção de DQO foi de $90 \%$, a média da alcalinidade total no efluente foi $72 \mathrm{mgCaCO} / \mathrm{L}$ e o índice volumétrico de lodo médio ficou em $86 \mathrm{~mL} / \mathrm{g}$. Estes resultados indicam que é possível utilizar RSB para o tratamento de esgoto doméstico com matéria orgânica reduzida sem comprometer a qualidade do efluente, a remoção de nitrogênio e a estabilidade operacional do sistema.

PALAVRAS-CHAVE: Reator seqüencial em batelada, RSB, remoção de nitrogênio, desnitrificação, lodos ativados, eficiência.

\begin{abstract}
This work had the objective of evaluating the SBR efficiency and stability in the removal of nitrogen on the treatment of domestic sewage with low COD. The reactor used in the experiment has a working volume of $600 \mathrm{~L}$, and treats $1200 \mathrm{~L} / d$ of raw sewage in three 8-hour cycles. From the data gathered during the research, it was realized that the $S B R$ fostered an average removal of total nitrogen equal to $88 \%$ in the treatment of a domestic sewage with an average COD of $257 \mathrm{mg} / \mathrm{L}$. The COD removal was $90 \%$, the final effluent total alkalinity was $72 \mathrm{mgCaCO} / \mathrm{L}$, and the sludge volumetric index was $86 \mathrm{~mL} / g$. The results indicate that is possible to use $S B R$ for the treatment of domestic sewage with low organic matter without compromising the final effluent quality, the nitrogen removal ability, and the stability of the system.
\end{abstract}

KEYWORDS: Sequencing batch reactor, SBR, nitrogen removal, denitrification, activated sludge, efficiency.

\section{INTRODUÇÃO}

Nas duas últimas décadas do século passado, o avanço tecnológico viabilizou a operação de sistemas de lodos ativados em batelada com a utilização mínima de mão-de-obra e de energia. Nesta mesma época, a busca de soluçôes mais compactas e eficientes para o tratamento de esgoto doméstico e a conscientização da sociedade sobre os efeitos da poluição hídrica na qualidade de vida alavancaram as pesquisas em saneamento. $\mathrm{O}$ sistema de lodos ativados de fluxo contínuo sempre teve um local de destaque no tratamento de águas residuárias domésticas por ser o mais utilizado em escala real e mais explorado em pesquisas. Entretanto, a remoção de nitrogênio de águas residuárias com DQO baixa sempre foi comprometida por falta de matéria orgânica para o processo de desnitrificação em sistemas de fluxo contínuo. Em conseqüência, a estabilidade operacional do sistema é afetada com a perda de lodo devido a flotação no decantador secundário e a redução na qualidade do efluente. A partir de pesquisas realizadas com RSB, defronta-se com uma variante de lodos ativados capaz de suprir a deficiência do sistema contínuo sem a necessidade de uso de fonte externa de carbono para estabelecer o controle do processo de desnitrificação. A 
valorização das áreas urbanas, a carência de tratamento terciário, a crescente necessidade de redução nas dimensões de estaçóes de tratamento de esgoto e a exigência cada vez maior por melhor qualidade de vida nas metrópoles devem impulsionar o desenvolvimento de pesquisas sobre reator seqüencial em batelada em curto espaço de tempo. A partir deste cenário, faz-se necessário desenvolver pesquisas voltadas à realidade brasileira sobre reator seqüencial em batelada. Assim, o presente trabalho tem como objetivos avaliar a eficiência e a estabilidade operacional do reator seqüencial em batelada na remoção de nitrogênio no tratamento de esgoto doméstico com DQO baixa.

\section{MATERIAIS E MÉTODOS}

O experimento foi montado no interior da ETE Vila Esmeralda, pertencente ao DMAE. O RSB em escala piloto, foi fabricado com chapa de ferro de $5 \mathrm{~mm}$ de espessura e está representado na Figura 1. O reator possui forma cilíndrica com altura de 1,50 m e diâmetro de 0,80 m. O sistema é alimentado por um conjunto elevatório (motor-bomba) instalado na casa de máquinas do experimento, localizada no interior da ETE. O conjunto elevatório é composto por uma bomba de deslocamento positivo, marca Netzsch modelo 2NP15A, e um motor trifásico, marca Weg. O efluente do reator é removido do RSB por meio de um conjunto elevatório semelhante ao da alimentação. Na base do reator está instalado um difusor de membrana, marca Nopol, alimentado por um compressor de ar com capacidade para $257 \mathrm{~L}$, marca Schulz. Na instalação de fornecimento de ar está montada uma válvula solenóide para liberar a passagem de ar nos períodos de aeração. Para evitar zonas mortas no RSB, foi instalado um motorredutor de 100 rpm com eixo vertical e uma hélice para promover a mistura do licor misto. $\mathrm{O}$ redutor da marca Geremia tem relação de $1 / 15$ e o motor elétrico trifásico da marca Weg desenvolve velocidade máxima de $1700 \mathrm{rpm}$. No interior do reator estão instaladas bóias para desligar os conjuntos elevatórios. Os volumes de trabalho, alimentação e descarte de efluente são 600, 400 e $400 \mathrm{~L}$ por ciclo, respectivamente. O RSB realiza três ciclos diários. Cada ciclo operacional (Figura 2) possui duração de 8 horas e é composto das seguintes fases: enchimento (uma hora), reação aeróbia (duas horas), reação anóxica (três horas), sedimen- tação (uma hora) e esvaziamento (uma hora). Para o controle do tempo de cada fase dos ciclos, existe um painel de comandos elétricos com timers analógicos ligados nos conjuntos elevatórios, na válvula solenóide e no sistema de agitação.

Em 05/08/2002, o reator foi inoculado com lodo da ETE Arvoredo do DMAE e colocado em operação. Ao longo da pesquisa, o RSB foi alimentado com esgoto doméstico que chegava na ETE Vila Esmeralda e era acumulado no poço úmido da estação. A idade de lodo utilizada foi 13 dias.

As coletas de amostras ocorreram entre 23/09 e 22/11/2002. Foram coletas amostras de esgoto bruto, efluente e lodo. O esgoto bruto e o tratado eram coletados nas fases de enchimento e descarga de efluente, respectivamente. $\mathrm{O}$ lodo era coletado no final da fase anóxica. Todas as amostras foram coletas na batelada que tinha início 8:00 e término 16:00 horas. Esta era a batelada com a maior carga de nitrogênio total. Após as coletas, as amostras eram acondicionadas em caixas de isopor com gelo e encaminhadas ao Laboratório de Saneamento
Ambiental do IPH/UFRGS. Nas amostras de esgoto bruto e efluente foram analisados os parâmetros DQO, sólidos totais, sólidos suspensos totais, nitrogênio amoniacal, nitrogênio Kjeldhal, nitrito, nitrato, temperatura, $\mathrm{pH}$ e alcalinidade total. No lodo foram determinados sólidos suspensos voláteis e índice volumétrico do lodo. Todos os parâmetros foram obtidos segundoo Standard Methods(1995).

\section{APRESENTACÃO E DISCUSSÃO DOS RESULTADOS OBTIDOS}

Os valores médios dos parâmetros analisados estão apresentados na Tabela 1. A partir dos dados desta tabela, observase que a remoção média de DQO foi $90 \%$. As concentrações de DQO, plotadas na Figura 3, revelam que houve uma redução acentuada na concentração de matéria orgânica no esgoto bruto após 27/09/2002. Esta diluição do afluente da ETE Esmeralda está diretamente ligada ao aumento das precipitaçōes pluviométricas agravado pelo efeito El Niño. Apesar das variações na concentração de

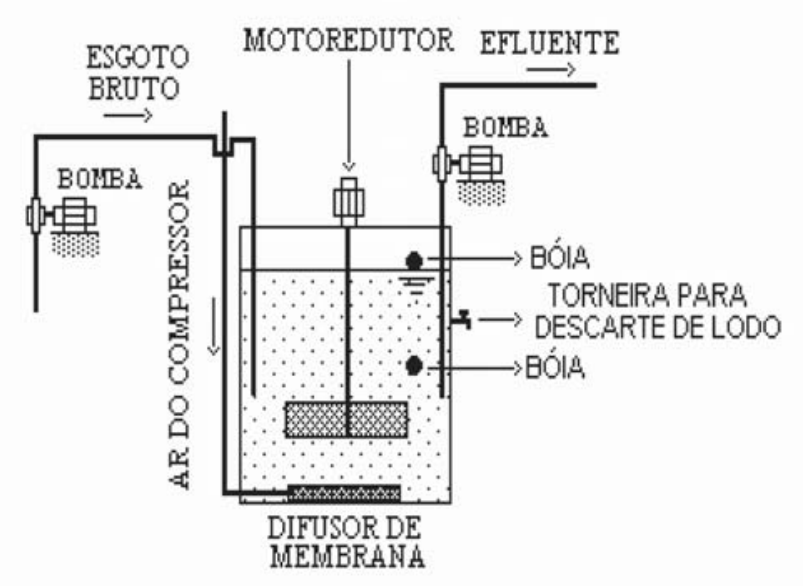

Figura I - Representação esquemática do RSB

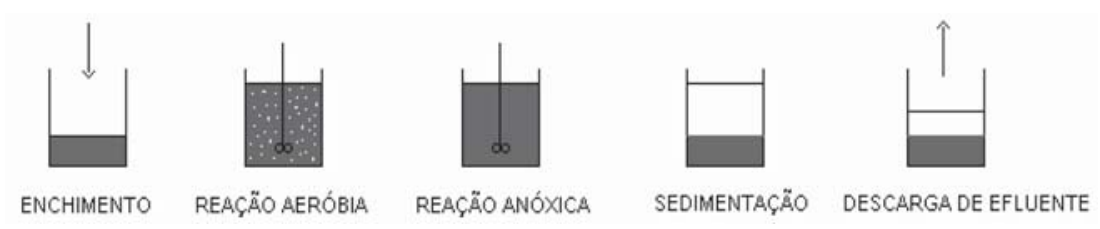

Figura 2 - Representação esquemática de um ciclo operacional 
matéria orgânica no afluente, o reator manteve uma concentração média de sólidos suspensos voláteis de $2874 \mathrm{mg} / \mathrm{L}$ (Tabela 1)

As concentrações de matéria orgânica no efluente mantêm uma regularidade mais acentuada e não recebem influência significativa das variaçóes do esgoto bruto. A remoção elevada de DQO em sistema de lodos ativados está ligada ao metabolismo bacteriano, uma vez que um terço da matéria orgânica afluente é oxidada e dois terços são incorporados ao lodo (Marais e Ekama, 1976). A capacidade de adsorção e sedimentação do lodo em reator seqüencial em batelada é preponderante na remoção de material particulado. As partículas sólidas orgânicas adsorvidas são armazenadas e hidrolisadas (Dold et al., 1980). Segundo estes pesquisadores, os compostos liberados após a hidrólise são metabolizados pela biomassa presente no reator. Os sólidos inertes adsorvidos ao lodo são removidos do reator através do descarte do lodo. Após as fases de reação aeróbia e anóxica, a separação sólidos-líquido se aproxima das condiçōes ideais em função do comportamento hidráulico do reator, contribuindo para o aumento da eficiência na remoção de material particulado. As médias das concentraçôes de sólidos totais e sólidos suspensos totais (Tabela 1) indicam que a maior fração de sólidos no efluente está na forma solúvel.

Verificando as Figuras 4, 5 e 6, constata-se que as concentrações de nitrogênio amoniacal, Kjeldahl e total no esgoto bruto demonstram a ocorrência de diluição do afluente da ETE Vila Esmeralda. As maiores concentrações de nitrogênio na água residuária ocorreram no início da pesquisa. Além disso, fica claro que a maior fração de nitrogênio presente no afluente está concentrada na forma amoniacal. A partir dos dados obtidos, observa-se que a remoção média do nitrogênio total foi $88 \%$.

Os dados da figura 7 revelam redução na alcalinidade total entre o esgoto bruto e o efluente do RSB. A concentração média no esgoto tratado foi $72 \mathrm{mgCaCO}_{3} \mathrm{mg} / \mathrm{L}$ (Tabela 1 ), superando o valor de $30 \mathrm{mgCaCO}{ }_{3} \mathrm{mg} / \mathrm{L}$ recomendado por van Haandel e Marais (1999) para evitar quedas bruscas de $\mathrm{pH}$. Este cenário justifica a ocorrência de nitrificação durante a aeração, uma vez que a alcalinidade consumida na oxidação da amônia não é totalmente recuperada na desnitrificação ao longo da fase anóxica (Sharma e Ahlert, 1977). Logo, percebe-se que parte da remoção de nitro-

Tabela I - Médias dos parâmetros analisados no esgoto bruto, no efluente final e no licor misto do RSB

\begin{tabular}{cccc}
\hline Parâmetro & Esgoto Bruto & Efluente final & Licor misto \\
\hline DQO $(\mathrm{mg} / \mathrm{L})$ & 257 & 25 & - \\
Sólidos totais $(\mathrm{mg} / \mathrm{L})$ & 738 & 280 & - \\
Sólidos suspensos totais $(\mathrm{mg} / \mathrm{L})$ & 128 & 19 & - \\
Nitrogênio amoniacal $(\mathrm{mgN} / \mathrm{L})$ & 25,3 & 2,5 & - \\
Nitrogênio Kjeldahl $(\mathrm{mgN} / \mathrm{L})$ & 38,4 & 4,6 & - \\
Nitrato $(\mathrm{mgN} / \mathrm{L})$ & - & 0,1 & - \\
Nitrito $(\mathrm{mgN} / \mathrm{L})$ & - & 0,0 & - \\
Nitrogênio total $(\mathrm{mgN} / \mathrm{L})$ & 38,4 & 4,7 & - \\
pH & 7,0 & 7,0 & - \\
Alcalinidade total $(\mathrm{mgCaCO} / \mathrm{L})$ & 144 & 72 & - \\
Temperatura $\left({ }^{\circ} \mathrm{C}\right)$ & 20 & 19 & 2874 \\
Sólidos suspensos voláteis $(\mathrm{mg} / \mathrm{L})$ & - & - & - \\
Índice volumétrico de lodo $(\mathrm{mL} / \mathrm{g})$ & - & &
\end{tabular}

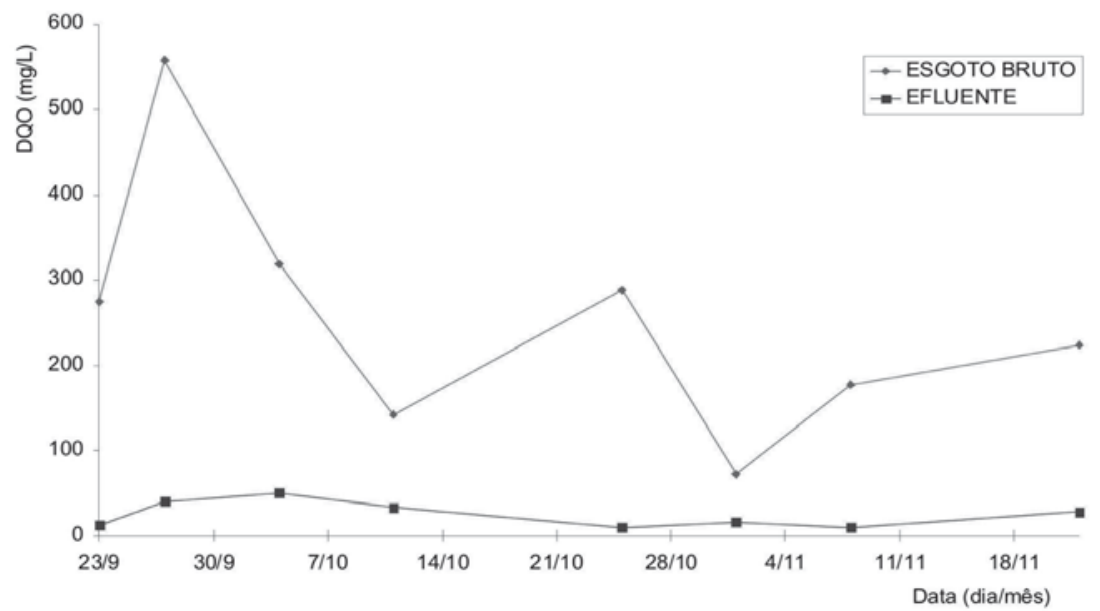

Figura 3 - Demanda química de oxigênio no esgoto bruto (EB) e no efluente final (EF)

gênio pode ser atribuída a desnitrificação. Outra parte do nitrogênio afluente é incorporada à biomassa e deixa o reator no descarte de lodo. Segundo Nielsen (1996), o nitrogênio amoniacal na forma de íon que é adsorvido ao lodo também será removido através do descarte de lodo.

A diferença entre os dados das Figuras 5 e 6 mostra que as concentraçóes de nitrato no efluente do reator seqüencial em batelada foram insignificantes na composição do nitrogênio total presente no efluente final. É importante ressaltar que não foi encontrado nitrito em nenhuma amostra coleta ao longo da pesquisa. A predominâncias do nitrogênio Kjeldahl no esgoto tratado está ligada ao nitrogênio amoniacal liberado de compostos orgânicos durante a fase anóxica e a presença de substâncias orgânicas nitrogenadas não-biodegradáveis. Segundo Cybis (1992), o desempenho de reatores seqüenciais em batelada na remoção de nitrogênio está associado à liberação de compostos orgânicos solúveis decorrentes do processo endógeno na fase anóxica. É prudente também considerar a contribuição da hidrólise de compostos orgânicos de degradação lenta. Estas formas de doadores de elétrons são imprescindíveis 


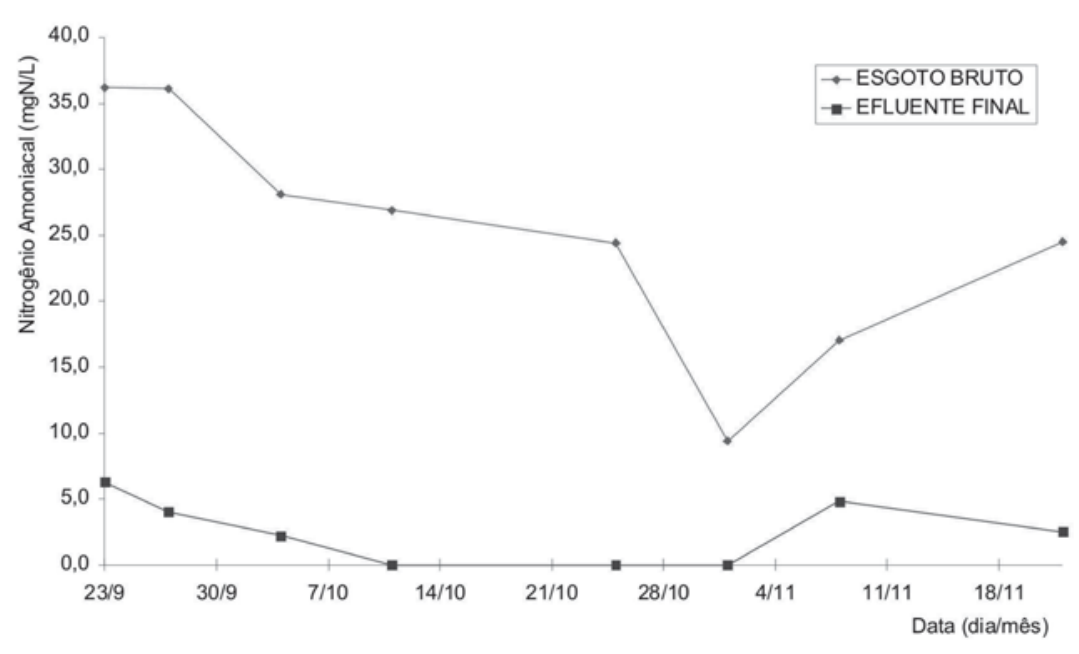

Figura 4 - Nitrogênio amoniacal no esgoto bruto (EB) e no efluente final (EF)

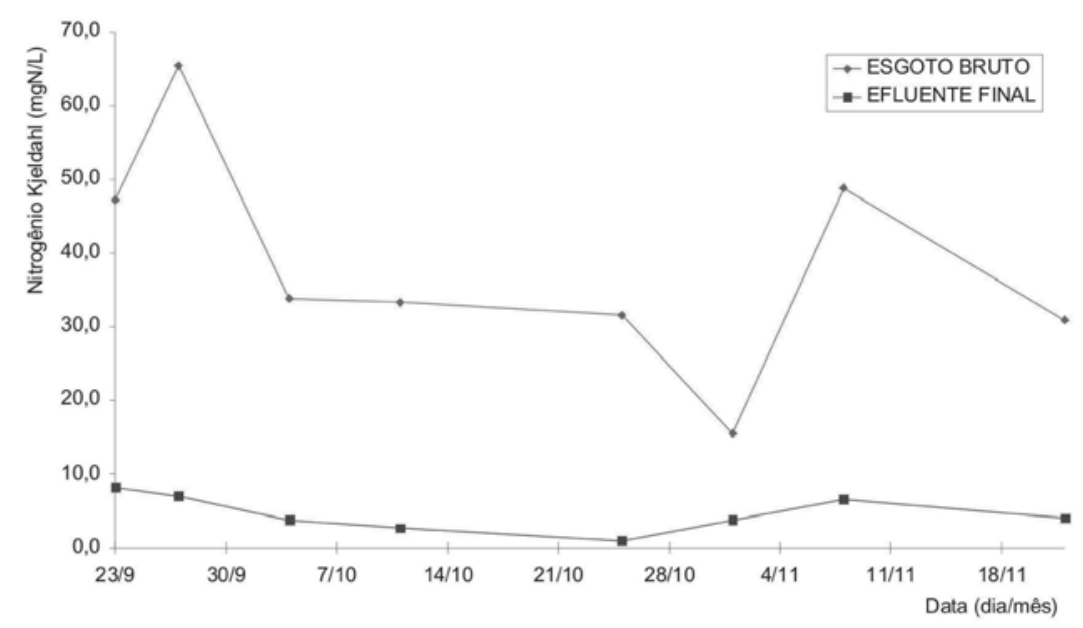

Figura 5 - Nitrogênio Kjeldhal no esgoto bruto (EB) e no efluente final (EF)

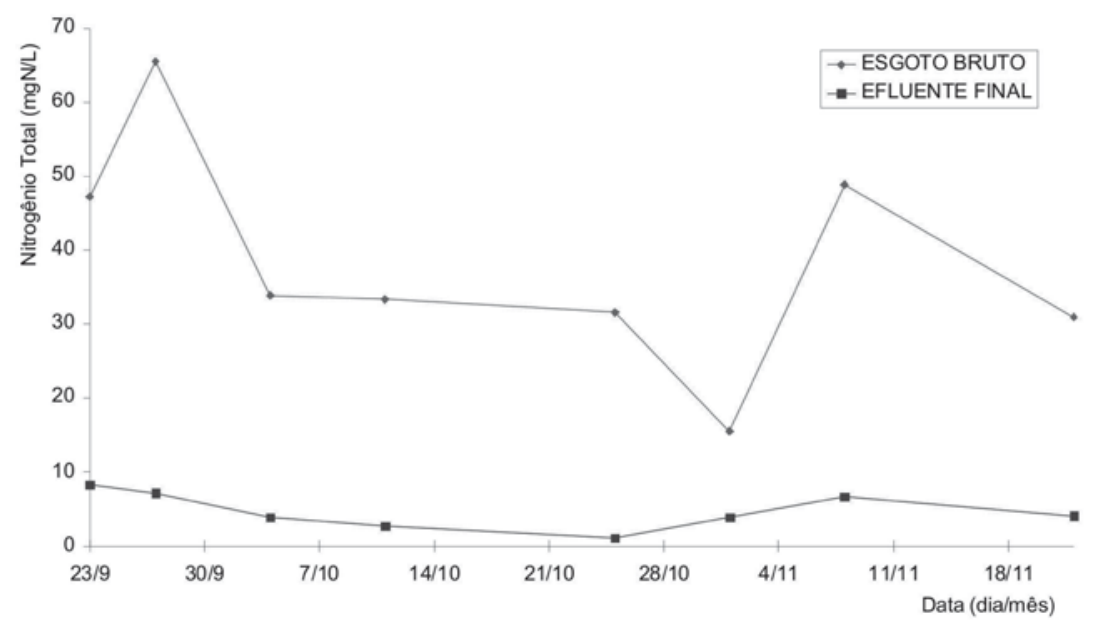

Figura 6 - Nitrogênio total no esgoto bruto (EB) e no efluente final (EF) para ocorrência da desnitrificação em reatores seqüenciais em batelada.

Os valores médios de $\mathrm{pH}$ no esgoto bruto e no efluente final (Tabela 1) confirmam que a nitrificação não desestabilizou os processos de remoção de matéria orgânica e nitrogênio. As médias de temperatura (Tabela 1 ) revelam que o comportamento hidráulico do RSB não promove queda elevada no grau de agitação molecular do efluente, quando o reator é exposto às variaçôes climáticas da primavera no Rio Grande do Sul. O IVL médio apresentado na tabela 1 foi igual a $86 \mathrm{~mL} / \mathrm{g}$. Uma avaliação simplificada do lodo permite afirmar que a sedimentabilidade obtida foi boa de acordo com von Sperling (1997). Em linhas gerais, as condiçôes operacionais do reator seqüencial em batelada refletem sua capacidade de suportar variações na DQO do esgoto bruto sem comprometer os processos de remoção de matéria orgânica e nitrogênio. Com isso, pode-se ressaltar o desempenho do RSB na remoção de nitrogênio tratando esgoto com DQO baixa.

\section{CONCLUSÕES}

O RSB se apresentou estável no tratamento de esgoto doméstico com DQO baixa. As concentrações de matéria orgânica no esgoto bruto não foram obstáculos para remoção de nitrogênio. Observou-se remoção deste parâmetro de $88 \%$ sem adição de fonte externa de carbono. Esta eficiência foi alcançada, provavelmente, a partir da contribuição de matéria orgânica liberada do processo endógeno e da hidrólise de compostos orgânicos de degradação lenta. As características hidráulicas do reator seqüencial em batelada possibilitam explorar o decaimento endógeno das bactérias para o fornecimento de doadores de elétrons durante a fase anóxica da batelada. É importante enfatizar que em nenhum momento a remoção de nitrogênio foi estabelecida durante a fase de sedimentação. As observações in loco não revelaram flotação de lodo e nem o monitoramento do efluente final mostrou presença excessiva de sólidos suspensos voláteis. Paralelamente, o processo de nitrificação não comprometeu a atividade das bactérias envolvidas no tratamento do esgoto, uma vez que a média da alcalinidade total do efluente foi superior a $30 \mathrm{mgCaCO} / \mathrm{L}$. Outro fato relevante para o desempenho do RSB foi à redução pequena na temperatura do esgoto bruto para o efluente. Observa-se que as características hidráu- 


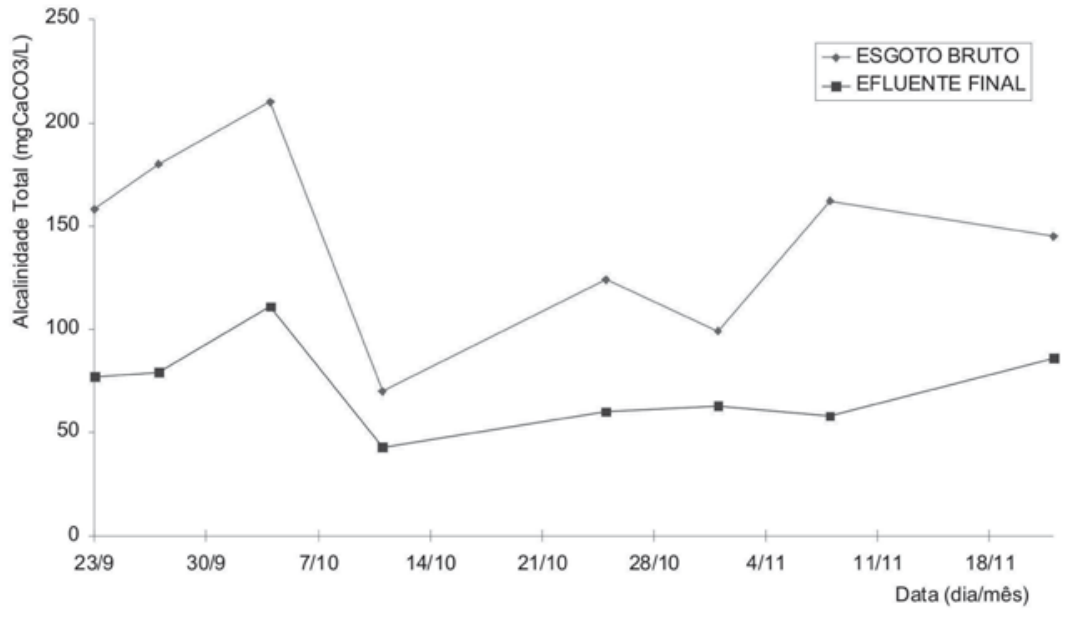

Figura 7 - Alcalinidade total no esgoto bruto (EB) e no efluente final (EF)

licas do reator não oferecem riscos ao desempenho do sistema no tratamento de esgoto doméstico em local com variações climáticas elevadas. A partir dos resultados obtidos, fica evidente que é possível remover nitrogênio em lodos ativados tratando esgoto doméstico com DQO baixa e sem gastos com uma fonte de carbono para estabelecer a desnitrificação sem comprometer a qualidade do efluente. Além disso, o reator não depende de mãode-obra especializada para operar de forma eficiente e possui um potencial elevado para automação do funcionamento e do controle dos processos biológicos.

\section{AGRADECIMENTOS}

Conselho Nacional de Desenvolvimento Científico e Tecnológico - CNPq, Instituto de Pesquisas Hidráulicas - IPH/ Universidade Federal do Rio Grande do Sul - UFRGS, Departamento Municipal de Água e Esgotos - DMAE de Porto Alegre, Centro Federal de Educação Tecnológica da Bahia - CEFET-BA.

\section{REFERÊNCIAS}

APHA - AWWA - WPCF (1995). Standard Methods for the Examination of Water and
Wastewater. American Public Health Association $19^{\mathrm{a}}$ Edition, Washington DC

CYBIS, L. F. An Innovative Aproach to the Control of Sequencing Batch Reactors Used for Nitrification and Denitrification. Departament of Civil Engineering. University of Leeds: Leeds, 240 p. (Tese de Doutorado em Engenharia Civil). 1992.

DOLD, P. L., EKAMA, G. A., MARAIS, G. R. A general model for the activated sludge process. Prog. Wat. Tech., v. 12. P. 47-77, 1980.

NIELSEN, P. H. Adsorption of ammonium to activated sludge. Water Research, v. 30, n. 3, p. 762-764, 1996

SHARMA, B.; AHLERT, R. C. Nitrification and nitrogen removal. Water Research, v. 11, p. 897-925, 1977.

VAN HAANDEL, A. C., MARAIS, G. v. R. O Comportamento do Sistema de Lodo Ativado: teoria e aplicaçôes para projetos e operaçôes. Campina Grande: epgraf, 472 p. 1999.

VON SPERLING, M. Lodos Ativados. Belo Horizonte: Departamento de Engenharia Sanitária e Ambiental - Universidade Federal de Minas Gerais, 415 p. (Princípios do Tratamento Biológico de Águas Residuárias, 4). 1997.

\section{Endereço para correspondência:}

Luiz Fernando de Abreu Cybis

Av. Bento Gonçalves, 9500

Caixa Postal I5.029

9 I50 I-970 - Porto Alegre - RS

Brasil

Tel.: (5 I) 33 I 6-6567

E-mail: Ifcybis@iph.ufrgs.br

\section{$23^{\circ}$ Congresso Brasileiro de Engenharia Sanitária e Ambiental}

\section{Saneamento ambiental no Brasil: Utopia ou Realidade?}

18 a 23 de setembro de 2005

Centro de Exposições Albano Franco

Campo Grande - MS 